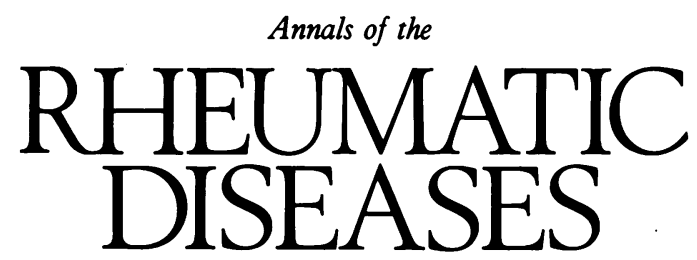

Leader

\title{
Where are peripheral analgesics acting?
}

Most chronic rheumatic diseases result in pain, deformities, and decreased functional ability. Interestingly, a substantial number of patients, including rheumatoid patients, rank pain relief as the most desirable objective of treatment. ${ }^{1}$ In this respect, the non-narcotic analgesics are usually considered as the best drugs. ${ }^{2-4}$ These agents mainly include paracetamol, salicylates, and other non-steroidal antiinflammatory drugs (NSAIDs), and non-acidic pyrazolone derivatives-for example, dipyrone (metamizole) and phenazone (antipyrine); aminophenazone (aminopyrine) has been withdrawn from the market. ${ }^{5}$ As a group, they share analgesic, antipyretic, and, to a greater or lesser extent, antiinflammatory properties. ${ }^{2}$ Conversely, these compounds show marked differences in their therapeutic action and side effects. ${ }^{2-5}$ Their common denominator was thus believed to be their site of action within the damaged tissues, ${ }^{6}$ and hence they were termed 'peripheral analgesics'.

This assumption was mainly based on the following findings. Firstly, the classic cross-circulation experiment performed in the $\operatorname{dog}$ by $\operatorname{Lim} e t a l^{7}$ indicated that the analgesic effect of aspirin-like drugs occurred in the pain producing site itself rather than in the central nervous system. Secondly, injections of minute amounts of acetylsalicylic acid, indomethacin, or paracetamol into the inflamed paws of rats were shown to attenuate the nociceptive responses. ${ }^{8}$ Moreover, NSAIDs may alter perceived pain intensity in rodents when applied locally to the injured sites. ${ }^{10}$ In humans too, locally applied aspirin and paracetamol appeared to be effective for controlling pain in the early postoperative period after third molar surgery. ${ }^{11}$ Thirdly, pharmacokinetic data are consistent with the peripheral activity of these drugs. ${ }^{5} 12$ Systemically administered NSAIDs were found to achieve particularly high concentrations in their target tissues in animals ${ }^{5}$ as well as in humans. ${ }^{1314}$ Finally, the analgesic property of aspirin-like drugs might be ascribed to their ability to inhibit prostaglandin biosynthesis. ${ }^{6} 15$ Indeed any tissue damage related to trauma, ischaemia, hyperthermia, or inflammation results in the release of various chemical substances, including prostaglandins, which may sensitise the primary afferent nociceptors to pain mediators, such as bradykinin. ${ }^{16}$ However, this mechanism of action has been questioned. ${ }^{17} 18$

Furthermore, experimental and clinical studies support the possibility of an additional central component in the analgesic action of aspirin-like drugs. This paper aims at reviewing these challenging findings.

Centrally mediated analgesic effect of aspirin-like drugs The central analgesic effect of aspirin-like drugs can be directly assessed by injecting them into the central nervous system in various in vivo models of acute pain. In this way very low doses of indomethacin or acetylsalicylic acid or paracetamol influenced in a dose-related manner the hyperalgesia associated with intraplantar injections of carrageenin into the rat paws. ${ }^{8}$ The potency of intraventricular aspirin was estimated to be about 50 times greater than that after the intraperitoneal dosing in the tooth pulp stimulation test in conscious monkeys. ${ }^{19}$ As intracerebroventricularly administered aminophenazone, unlike tolmetin sodium, attenuated the writhing response evoked by the intraperitoneal injection of dilute acetic acid in rodents, it was suggested that only non-acidic compounds may act centrally. ${ }^{20}$ Aspirin, however, an acidic drug, proved effective in the same test on intrathecal administration. ${ }^{21}$ There are other conflicting results. For instance, it was reported that intraventricular salicylic acid inhibited the lame walking reaction induced by an acute inflammatory hind paw oedema, whereas ketoprofen and flurbiprofen did not. ${ }^{10} \mathrm{On}$ the other hand, intraventricular ketoprofen seemed to produce a dose dependent effect in the tail withdrawal assay, in which the rat tail was immersed in hot water. ${ }^{22}$ It should be remembered that both false negative and false positive results may occur in analgesic screening tests, and thus no single experiment allows a definite conclusion to be drawn. ${ }^{23}$ In this respect, the data provided by central administration of aspirin are the most convincing. They prompted several authors to treat patients with severe chronic pain by intrathecal injections of aspirin. ${ }^{24} 25$ This resulted in longlasting pain relief, especially in patients presenting with bone metastases. ${ }^{25}$

Whether systemically administered aspirin-like drugs too produce a central analgesic effect has now to be ascertained. It was assumed that non-narcotic analgesics merely act in those areas in which they achieve high concentrations. ${ }^{5}$ Accordingly, several NSAIDs and paracetamol were found to cross rapidly the blood-brain barrier in animals ${ }^{26} 27$ and in humans. ${ }^{28-30}$ Equilibrium was reached within a few hours and their cerebrospinal fluid concentrations were close to their free plasma concentrations. ${ }^{28}$ Experimental assays provided further indirect evidence of a central impact of these compounds. Some of them ${ }^{23}{ }^{31}$ were active in animal models of acute pain that are usually considered as specifically responsive to the opiates. ${ }^{23}$ Sodium salicylate suppressed the escape responses elicited by electrical stimulations of the lateral hypothalamus in rats when given subcutaneously. ${ }^{32}$ These findings were corroborated by clinical studies. A single oral dose of about $1 \mathrm{~g}$ of aspirin influenced pain related cerebral potentials in response to non-inflammatory noxious stimuli. ${ }^{33}$ Another commonly 
used assay for evaluating the central effect of analgesics is the nociceptive flexion reflex of the leg (RIII). This spinal reflex is correlated with the sensation of pain induced by transcutaneous electrical stimulations of the sural nerve at the ankle. ${ }^{35}$ Intravenous administration of either ketoprofen $100 \mathrm{mg}^{35}$ or paracetamol $1 \mathrm{~g},{ }^{36}$ increased significantly both the subjective pain threshold and the RIII reflex threshold as compared with placebo in healthy volunteers. An intramuscular dose of indomethacin $50 \mathrm{mg}$ produced a similar effect in rheumatic patients. ${ }^{37}$ In contrast, a short intravenous infusion of $1 \mathrm{~g}$ acetylsalicylic acid had no noticeable effect on either threshold. ${ }^{36}$ These findings are consistent with the clinical pharmacokinetics of these drugs in the cerebrospinal fluid. ${ }^{28-30}$ Moreover, the time-effect curve of paracetamol ${ }^{36}$ resembles its concentration-time profile in the cerebrospinal fluid. ${ }^{30}$ Though in disagreement with other reports, ${ }^{33}{ }^{34}$ the lack of effect of acetylsalicylic acid may be explained by the poor permeability of the blood-brain barrier to very low lipophilic molecules. ${ }^{28}$ This does not preclude, however, the possibility of a central analgesic action of salicylates. Higher doses may promote the diffusion of salicylates into the central nervous system by increasing their free fraction in the plasma. ${ }^{28}$

Most of these studies suggest that aspirin-like drugs exert a direct analgesic effect at some levels of the neuraxis, as do other kinds of non-narcotic analgesics, such as nefopam and flupirtine. ${ }^{38}$ As opiates were shown to exert a peripheral analgesic action in addition to their well known central effects, ${ }^{39}$ a clear cut discrimination between peripheral and central analgesics is debatable. The peripheral analgesic activity of aspirin-like drugs is not disproved, however. The analgesia produced by both peripheral and central mechanisms may be additive, or even synergistic. ${ }^{8}$ The relative contribution of each site of action to the overall analgesia remains to be established ${ }^{82} 29$ and may vary from one compound to another.

\section{Mechanisms underlying the central analgesic effect}

Several sites and mechanisms have been proposed for the central analgesic effect of aspirin-like drugs. Before reviewing them, we outline briefly some aspects of the nociceptive system. ${ }^{40-42}$ Pain messages originating from nociceptors are mainly conducted by thin myelinated $A \delta$ and unmyelinated $C$ fibres which terminate in the dorsal horn of the spinal cord. When pain signals arrive at this level they induce the release of various transmitters, including neuropeptides such as substance $P$, neurokinin $A$, calcitonin gene related peptide, etc. Some of them activate neurones, which relay pain signals to thalamic nuclei, especially through the spinothalamic tract, and thence to different areas of the cortex. Transmission of nociceptive messages at the spinal level is under both segmental and supraspinal controls. The segmental endogenous opioid system and GABAergic cells seem to be implicated in the former, which may partly be linked to the 'gate control' mechanism described by Melzack and Wall. ${ }^{41}$ The latter consists of complex descending inhibitory pathways of cortex and brain stem origins. Important structures are located in the periaqueductal grey matter and the nucleus raphe magnus. The existence of connections between these areas should be pointed out. Despite gaps in our knowledge of these control systems it can be assumed that they operate as a negative feedback loop triggered by noxious stimuli. Monoamines (serotonin, norepinephrine) and endogenous opioid peptides appear to mediate the inhibitory effects on pain messages. For instance, the axons of serotoninergic neurones of the nucleus raphe magnus descend in the dorsolateral funiculus and terminate at different levels of the spinal cord, where they inhibit nociceptive inputs. In summary, both spinal and supraspinal sites might play a part in the analgesia induced by aspirin-like drugs.

Some findings support the first possibility. Intrathecally administered substance $P$ in mice elicited a pain-related behavioural response that was reduced by systemic pretreatment with either paracetamol or aspirin. ${ }^{43}$ Similar results were obtained on intrathecal administration of capsaicin, which provokes the release of substance $P$ in the dorsal horn of the spinal cord. ${ }^{43}$ Therefore, it was concluded that both drugs may act by interfering with the function of the substance $P$ receptors or by inhibiting neurones excited by substance $P{ }^{43}$

Most studies, however, underline the crucial role of supraspinal structures. Ketoprofen did not display any significant effect on the nociceptive reflex (RIII) in paraplegic patients with a complete spinal section of traumatic origin, whereas it provided a clear depressive effect in normal subjects. ${ }^{44}$ Moreover, pyrazolone derivatives, aspirin and paracetamol were reported to depress the activity evoked in the dorsomedial part of the ventral nucleus of the thalamus by electrical stimulation of nociceptive afferents in the rat sural nerve. ${ }^{45}$ This effect may be related, at least in part, to an activation of some supraspinal inhibitory pathways of nociception. ${ }^{45}$ As a result, pain messages are blocked in the spinal cord so that they do not reach higher centres. This hypothesis was reinforced by other experiments. As the analgesia induced by intrahypothalamic microinjections of aspirin in conscious monkeys was antagonised by pretreatment with either serotonin or catecholamine receptor blockers, it was suggested that aspirin may activate monoaminergic control systems. ${ }^{46}$ Similarly, the depressive effect of intravenous administration of aspirin on the firing discharge of thalamic neurones elicited by noxious stimuli in rats was counteracted by pretreating the animals with a serotonin receptor antagonist. ${ }^{47}$ The activation of the descending serotoninergic inhibitory pathway may also account for the analgesic effect of paracetamol. ${ }^{48}$ Interestingly, naloxone did not alter the central effects of aspirin-like drugs, indicating that endogenous opioids are not implicated in these processes. ${ }^{45} 4748$

Although alternative mechanisms have been proposed, such as an increase in pituitary $\beta$ endorphin secretion ${ }^{49}$ or a direct effect on the neurone membrane potential, ${ }^{37}$ monoamine systems appear to play an important part in the central analgesic effect of aspirin-like drugs. Whether this mechanism may be linked to prostaglandin biosynthesis inhibition will now be discussed.

\section{Central analgesic effect and prostaglandin inhibition} Aspirin-like drugs are well known inhibitors of prostaglandin synthetases of different tissue origins. Whether paracetamol impedes cyclo-oxygenase activity in the central nervous system selectively is debated. ${ }^{15} 50$ Salicylic acid, which is generally considered as a poor cyclo-oxygenase inhibitor on the basis of in vitro data, was found to be as potent as aspirin in preventing prostaglandin production in inflammatory exudates in vivo. ${ }^{51}$ Paracetamol and various NSAIDs, given by oral intubation, were reported to inhibit ischaemia-induced prostaglandin $E_{2}$ formation in mouse brain. ${ }^{52}$ Their degree of inhibition of mouse brain cyclooxygenase correlated well with their antinociceptive potencies in the acetylcholine induced constriction test. ${ }^{52}$

Several authors, especially Ferreira ${ }^{816}$ and Yaksh, ${ }^{21}$ provided further evidence for the involvement of prostaglandins in the central analgesic effect of these agents. Thus stimulation of peripheral nerves in animals resulted in an increase in extracellular prostaglandin concentrations in the central nervous system. ${ }^{21}$ Direct administration of prostaglandin $\mathrm{E}_{2}$ into the rat cerebral ventricles did not cause pain, 
but enhanced the hyperalgesia produced by concomitant intraplantar injection of prostaglandin $\mathrm{E}_{2}{ }^{8}$ Intrathecally administered prostaglandin $\mathrm{F}_{2 \alpha}{ }^{21}$ or prostaglandin $\mathrm{E}_{2}{ }^{53}$ lowered nociceptive thresholds. These observations suggest that noxious stimuli elicit the release of prostaglandin within the central nervous system, where it facilitates the processing of the pain messages. ${ }^{1621}$ It was therefore postulated that the inhibition of prostaglandin formation in the central nervous system might be relevant to the central analgesic effect of aspirin-like drugs. ${ }^{15} 1621$ This mechanism may account for the limited analgesic potential of these agents and their persistent efficacy during long term treatment as compared with the opiates. Indeed, prostaglandins serve only to facilitate pain processing, not to mediate it entirely, and inhibition of enzyme function is not subject to the development of tolerance. ${ }^{21}$

Inconsistencies in the reported central effect of prostaglandins on nociception have already been mentioned. ${ }^{43}$ They may be related to the bell shaped dose-response curves for the hyperalgesic action of prostaglandins. ${ }^{54}$ In other words, very low or very high concentrations of prostaglandins may produce similar effects that are opposite to those induced by moderate concentrations. This feature may be reconciled with a role for central prostaglandins as regulators of neurotransmitter release. ${ }^{54} 55$ Interactions between prostaglandins and a range of neuromediators have, in fact, been reported. ${ }^{21}$ 53-56 Taiwo and Levine showed that prostaglandin $E_{2}$ interacts with descending monoaminergic pathways that contribute to the down regulation of nociception. ${ }^{53}$ Furthermore, blockade of noradenergic synaptic transmission in the spinal cord eliminated the analgesic effects of intrathecally injected aspirin and indomethacin. ${ }^{53}$ Finally, prostaglandin $\mathrm{E}_{2}$ may inhibit pain control circuits in the central nervous system by blocking the release of norepinephrine from the spinal terminals of brain stem projection neurones. ${ }^{53}$

In summary, numerous studies indicate that aspirin-like drugs have a central analgesic effect on either inflammatory or non-inflammatory pain processes. These agents produce central analgesia without sensory, motor, or autonomic side effects. ${ }^{24}$ Their exact sites and mode of action within the central nervous system are poorly defined, and even controversial. There are two main hypotheses. Firstly, these agents may act by inhibiting central prostaglandin formation induced by noxious stimuli. Secondly, their effect may be related to their ability to affect central neurotransmitters involved in pain processing and pain control. Provided that these data are reliable, the interactions between prostaglandins and neuromediators suggest that both mechanisms are probably linked.

Department of Clinical Pharmacology, BERNARD BANNWARTH Université de Bordeaux II E FABIENNE DEMOTES-MAINARD Groupe Hospitalier Pellegrin,

Bordeaux, France

Department of Rheumatology,

Université de Bordeaux II Eै

Groupe Hospitalier Pellegrin

Bordeaux, France

THIERRY SCHAVERBEKE JOËL DEHAIS

Correspondence to: Professor B Bannwarth, Service de Pharmacologie Clinique, CHR Pellegrin-Carreire, 33076 Bordeaux Cedex, France.

1 Gibson T, Clark B. Use of simple analgesics in rheumatoid arthritis. Ann Rheum Dis 1985; 44: 27-9.

2 Nuki G. Non-steroidal analgesics and anti-inflammatory agents. BMF 1983; 287: $39-43$.

3 Amadio P. Peripherally acting analgesics. Am J Med 1984; 77 (suppl 3A): 17-26.

4 Al Arfag A, Davis P. Osteoarthritis 1991. Current treatment regimens. Drugs 1991; 41: 193-201.

5 Brune K, Lan R. Mode of action of peripheral analgesics. Arzneimittelforsch Drug Res 1984; 34 (II): 1060-5.
6 Capetola R J, Rosenthal M E, Dubinsky B, McGuire J L. Peripheral antialgesics: a review, 7 Clin Pharmacol 1983; 23: 545-56.

7 Lim R K S, Guzman F, Rodgers D W, et al. Site of action of narcotic and non narcotic analgesics determined by blocking bradykinin-evoked viscera pain. Arch Int Pharmacodyn 1964; 152: 25-58.

8 Ferreira S H, Lorenzetti B B, Corrêa F M A. Central and periphera antialgesic action of aspirin-like drugs. Eur $\mathcal{f}$ Pharmacol 1978; 53: 39-48.

9 Guilbaud G, Iggo A. The effect of lysine acetylsalicylate on joint capsule mechan

0 Hechanoreceptors in rats with polyarthrits. Exp Bran Res 195, 61. 164-8. aspirin, and the site of analgesic action of salicylic acid. Int $\mathcal{Y}$ Tissue React 1986; 8: 327-31.

11 Moore U J, Seymour R A, Rawlins M D. The efficacy of locally applied aspirin and paracetamol in postoperative pain. Br f Clin Pharmacol 1991 31: 615P.

12 Bendele A M, Ruterbories K J, Spaethe S M, et al. Correlation of antiinflammatory activity with peak tissue rather than peak plasma levels of BF 389. F Pharmacol Exp Ther 1992; 260: 1194-8.

13 Wallis W J, Simkin P A. Antirheumatic drug concentrations in human synovial fluid and synovial tissue. Observations on extravascular pharmacokinetics. Clin Pharmacokinet 1983; 8: 496-522.

14 Bannwarth B, Netter P, Lapicque F, et al. Tenoxicam concentrations in synovium and joint cartilage in humans. Agents Actions 1991; 32: 295-8.

15 Vane J R. Inhibition of prostaglandin synthesis as a mechanism of action for aspirin-like drugs. Nature New Biol 1971; 231: 232-5.

16 Ferreira S H. Peripheral analgesia: mechanism of the analgesic action of aspirin like drugs and opiate antagonists. Br f Clin Pharmacol 1980; 10 (suppl 2): 237S 45 S

17 McCormack K, Brune K. Dissociation between the antinociceptive and antiinflammatory effects of the nonsteroidal anti-inflammatory drugs. A survey of their analgesic efficacy. Drugs 1991; 41: 533-47.

18 Brune K, Beck W S, Geisslinger G, Menzel-Soglowek S, Peskar B M, Peska B A. Aspirin-like drugs may block pain independently of prostaglandin synthesis inhibition. Experientia 1991; 47: 258-61.

19 Shyu K W, Lin M T, Wu T C. Possible role of central serotoninergic neurons in the development of dental pain and aspirin-induced analgesia in the monkey. Exp Neurol 1984; 84: 179-87.

20 Nakamura $H$, Shimoda A, Ishii $K$, Kadokawa $T$. Central and periphera analgesic action of non-acidic non-steroidal anti-inflammatory drugs in mice and rats. Arch Int Pharmacodyn 1986; 282: 16-25.

21 Yaksh T L. Central and peripheral mechanisms for the antialgesic action of acetylsalicylic acid. In: Barnett $H$ M J, Hirsh J, Mustard J F, eds. Acetylsalicylic acid: new uses for an old drug. New York: Raven Press, 1982: Acetylsalicy $137-51$.

22 Rampin O, Harrewyn J M, Albe-Fessard D. Effet antalgique de l'administration centrale du kétoprofene chez le rat. Rev Rhum Mal Osteoartic 1988 55: $779-80$.

23 Chau T T. Analgesic testing in animal models. In: Chang J Y, Lewis A J, eds. Pharmacological methods in the control of inflammation. New York: Alan R Riss, 1988: 195-212.

24 Devoghel J C. Small intrathecal doses of lysine-acetylsalicylate relieve intractable pain in man. 7 Int Med Res 1983; 11: $90-1$.

25 Pellerin M, Hardy F, Abergel A, et al. Douleur chronique rebelle des cancéreux. Intérêt de l'injection intrarachidienne d'acétylsalicylate de lysine. Soixante observations. Presse Med 1987; 16: 1465-8.

26 Ochs H R, Greenblatt D J, Abernethy D R, et al. Cerebrospinal fluid uptake and peripheral distribution of centrally acting drugs: relation to lipid solubility. $\mathcal{J}$ Pharm Pharmacol 1985; 37: 428-31.

27 Cheney-Thamm J, Alianello E A, Freed C T, Reite $M$. In vivo electrochemical recording of acetaminophen in non human primate brain. Life Sci 1987; 40: 375-9.

28 Bannwarth B, Netter P, Pourel J, Royer R J, Gaucher A. Clinical pharmacokinetics of nonsteroidal anti-inflammatory drugs in the cerebrospinal fluid. Biomed Pharmacother 1989; 43: 121-6.

29 Bannwarth B, Netter P, Lapicque F, Péré P, Thomas P, Gaucher A. Indomethacin plasma and cerebrospinal fluid concentrations in humans. Relationship with the analgesic activity. Eur f Clin Pharmacol 1990; 38 : 343-8.

30 Bannwarth B, Netter P, Lapicque F, et al. Plasma and cerebrospinal fluid concentrations of paracetamol after a single intravenous dose of propacetamol. Br f Clin Pharmacol 1992; 34: 79-81.

31 Brogden R N. Pyrazolone derivatives. Drugs 1986; 32 (suppl 4): 60-70.

32 Dubas T C, Parker J M. A central component in the analgesic action of sodium salicylate. Arch Int Pharmacodyn 1971; 194: 117-22.

33 Chen A C N, Chapman C R. Aspirin analgesia evaluated by event-related potentials in man: possible central action in brain. Exp Brain Res 1980; 39 359-64.

34 Bromm B, Rundshagen I, Scharein E. Central analgesic effects of acetylsalicylic acid in healthy men. Arzneimittelforsch Drug Res 1991; 41 (II): 1123-9.

35 Willer J C, Harrewyn J M. Effet inhibiteur central du kétoprofene intraveineux sur le réflexe nociceptif de flexion chez l'homme. Presse Med 1987; 16: 63-7.

36 Piletta P, Porchet H C, Dayer P. Central analgesic effect of acetaminophen but not of aspirin. Clin Pharmacol Ther 1991; 49: 350-4.

37 Guieu R, Blin O, Pouget J, Serratrice G. Analgesic effect of indomethacin shown using the nociceptive flexion reflex in humans. Ann Rheum Dis 1992 51: $391-3$.

38 Bannwarth B, Chaslerie A, Schaeverbeke T, Vinçon G, Dehais J, Bégaud B. Modes d'action des antalgiques non morphiniques. Rev Rhum $M a$ Osteoartic 1992; 59: 267-70.

39 Basbaum A I, Levine J D. Opiate analgesia. How central is a periphera target? N Engl f Med 1991; 325: 1168-9.

40 Fields H L. Neurophysiology of pain and pain modulation. Am 7 Med 1984 77 (suppl 3A): 2-8.

41 Besson J M, Chaouch A. Peripheral and spinal mechanisms of nociception. Phusiol Rev 1987; 67: 67-186.

42 Woolf C J. Generation of acute pain: central mechanisms. Br Med Bull 1991; 47: $523-33$.

43 Hunskaar S, Fasmer O B, Hole K. Acetylsalicylic acid, paracetamol and morphine inhibit behavioral responses to intrathecally administered submorphine inhibit behavioral responses to intratheca
stance $P$ or capsaicin. Life Sci 1985; 37: 1835-41.

44 Willer J C, De Broucker T, Bussel B, Roby-Brami A, Harrewyn J M. Central analgesic effect of ketoprofen in humans: electrophysiological evidence for a 38: 1-7. 
45 Carlsson K H, Monzel W, Jurna I. Depression by morphine and the non opioid analgesic agents, metamizol (dipyrone), lysine acetylsalicylate, and paracetamol, of activity in rat thalamus neurones evoked by electrical stimulation of nociceptive afferents. Pain 1988; 32: 313-26.

46 Shyu K W, Lin M T. Hypothalamic monoaminergic mechanisms of aspirininduced analgesia in monkeys. $\mathcal{F}$ Neur Transm 1985; 62: 285-93.

47 Groppetti A, Braga P C, Biella G, Parenti M, Rusconi L, Mantegazza P. Effect of aspirin on serotonin and met-enkephalin in brain: correlation with the antinociceptive activity of the drug. Neuropharmacology 1988; 27 499-505.

48 Tjølsen A, Lund A, Hole K. Antinociceptive effect of paracetamol in rats is partly dependent on spinal serotoninergic systems. Eur F Pharmacol 1991; 193: 193-201.

49 Sacerdote P, Monza G, Mantegazza P, Panerai A E. Diclofenac and pirprofen modify pituitary and hypothalamic beta-endorphin concentrations. Pharmacological Research Communications 1985; 17: 679-84.

50 Bruchhausen F V, Baumann J. Inhibitory actions of desacetylation products of phenacetin and paracetamol on prostaglandin synthetases in neuronal and of phenacetin and paracetamol on prostaglandin synthetases in neuror
glial cell lines and rat renal medulla. Life Sci 1982; 30: 1783-91.

51 Higgs G A, Salmon J A, Henderson B, Vane J R. Pharmacokinetics of aspirin and salicylate in relation to inhibition of arachidonate cyclooxygenase and antiinflammatory activity. Proc Natl Acad Sci USA 1987; 84: 1417-20.

52 Ferrari R A, Ward S J, Zobre C M, et al. Estimation of the in vivo etfect of cyclooxygenase inhibitors on prostaglandin E2 levels in mouse brain. Eur 7 Pharmacol 1990; 179: 25-34.

53 Taiwo Y O, Levine J D. Prostaglandins inhibit endogenous pain contro mechanisms by blocking transmission at spinal noradrenergic synapses. I Neurosci 1988; 8: 1346-9.

54 Uda R, Horiguchi S, Ito S, Hyodo M, Hayaishi O. Nociceptive effects induced by intrathecal administration of prostaglandin $D_{2}, E_{2}$, or $F_{21}$ to induced by intrathecal administration of prost
conscious mice. Brain Res 1990; 510: 26-32.

55 Minocha A, Barth J T, Herold D A, Gideon D A, Spyker D A. Modulation of ethanol-induced central nervous system depression by ibuprofen. Clin Pharmacol Ther 1986; 39: 123-7.

56 Mariott D, Wilkin G P, Coote P R, Wood J N. Eicosanoid synthesis by spina cord astrocytes is evoked by substance $\mathbf{P}$; possible implications for nociception and pain. In: Samuelsson B, Ramwell P W, Paoletti R, Folco G, Grandstrom E, eds. Prostaglandins and related compounds. New York: Raven Press, 1991: 739-41.

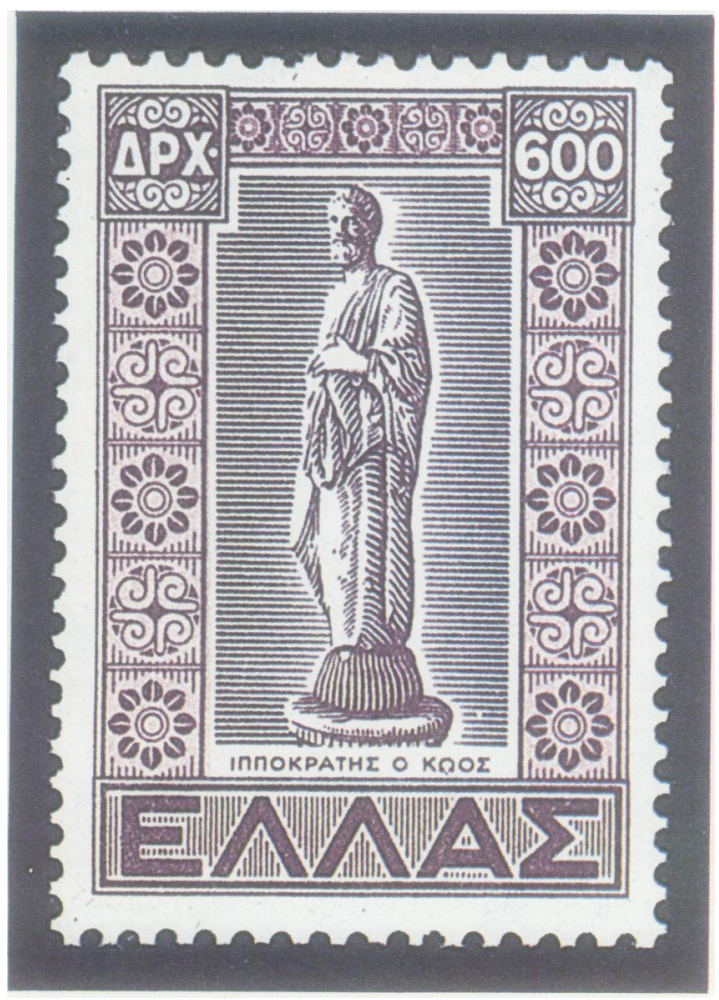

Hippocrates $(460-375 \mathrm{BC})$ is called the father of medicine. $\mathrm{He}$ built a system of medicine around the theory of the healing power of nature 'Vis medicatrix naturae': He and his pupils compiled the Corpus Hippocraticum, the medical treatise in which the term 'arthron' (joint) appears about 314 times. He describes what seems to be paediatric arthritis, gout, spondylosis, osteoarthritis, and ankylosing spondylitis. He discusses the use of climate and food in treatment. His keen observation was the keynote of his teachings. His knowledge of anatomy was weak as current religious beliefs did not sanction the use of necropsies. Also, his theories of the humours were incorrect.

YALE ANDELMAN 